\title{
Tumour necrosis factor inhibitors reduce aortic stiffness progression in patients with long-standing rheumatoid arthritis
}

\author{
Alessandro Giollo ${ }^{1,2^{*}} \mathbb{D}$, Giovanni Cioffi ${ }^{1,3}$, Federica Ognibeni ${ }^{1}$, Giovanni Orsolini ${ }^{1}$, Andrea Dalbeni ${ }^{4}$, Riccardo Bixio ${ }^{1}$, \\ Giovanni Adami ${ }^{1}$, Angelo Fassio ${ }^{1}$, Luca Idolazzi ${ }^{1}$, Davide Gatti ${ }^{1}$, Maurizio Rossini ${ }^{1}$ and Ombretta Viapiana ${ }^{1}$
}

\begin{abstract}
Background: Aortic stiffness index (AoSI) has to be considered a proxy outcome measure in patients with rheumatoid arthritis (RA). The aim of this study was to comparatively describe AoSI progression in two groups of RA patients on long-term treatment with conventional synthetic disease-modifying anti-rheumatic drugs (csDMARDs) with or without tumour necrosis factor inhibitors (TNFi).

Methods: AoSI was evaluated by Doppler echocardiography at the level of the aortic root, using a two-dimensional guided M-mode evaluation. Eligible participants were assessed at baseline and after 12 months. Changes in serum lipids, glucose and arterial blood pressure were assessed. All patients who did not change DMARD treatment during follow-up were consecutively selected for this study.

Results: We included 107 (64 TNFi and 43 csDMARDs) RA patients. Most patients (74\%) were in remission or low disease activity and had some CVD risk factors (45.8\% hypertension, 59.8\% dyslipidaemia, 45.3\% smoking). The two groups did not differ significantly for baseline AoSI $(5.95 \pm 3.73 \%$ vs $6.08 \pm 4.20 \%, p=0.867)$. Follow-up AoSI was significantly increased from baseline in the csDMARDs group $(+1.00 \%$; $p<0.0001)$ but not in the TNFi group $(+0.15 \%$, $p=0.477)$. Patients on TNFi had significantly lower follow-up AoSI from baseline than the csDMARDs group ( $-1.02 \%$, $p<0.001$; ANCOVA corrected for baseline AoSI, age and systolic blood pressure). Furthermore, follow-up AoSI was significantly lower in TNFi than in CSDMARDs users with an increasing number of CVD risk factors.
\end{abstract}

Conclusion: Long-term treatment with TNFi was associated with reduced aortic stiffness progression in patients with established RA and several CVD risk factors.

\section{Introduction}

Rheumatoid arthritis (RA) is a chronic immune-mediated and inflammatory disease characterized by a $48 \%$ increased risk of cardiovascular (CV) events and a 50\% higher incidence of cardiovascular disease (CVD)-related mortality compared with the general population $[1,2]$.

\footnotetext{
*Correspondence: alessandro.giollo@univr.it

${ }^{1}$ Rheumatology Section, Department of Medicine, University of Verona Hospital Trust, Policlinico G.B. Rossi 10, 37134 Verona, Italy ${ }^{2}$ Division of Rheumatology, University of Padova, Padua, Italy Full list of author information is available at the end of the article
}

There is growing evidence that increased arterial stiffness may account for the excess risk of CVD in RA [3-8]. Arterial stiffness is one of the earliest detectable manifestations within the atherosclerotic vessel wall $[9,10]$, and it acts as a strong independent predictor of $\mathrm{CV}$ events and all-cause mortality in various populations [11]. When structural and functional changes of the elastic fibres within the arterial wall occur, arteries progressively lose their low-stretch bearing component, longitudinal elasticity and geometry, leading to collagen deposition with decreased elasticity and stiffness, elongation and increased tortuosity [12]. While this phenomenon is strictly related

(c) The Author(s). 2021 Open Access This article is licensed under a Creative Commons Attribution 4.0 International License, which permits use, sharing, adaptation, distribution and reproduction in any medium or format, as long as you give appropriate credit to the original author(s) and the source, provide a link to the Creative Commons licence, and indicate if changes were made. The images or other third party material in this article are included in the article's Creative Commons licence, unless indicated otherwise in a credit line to the material. If material is not included in the article's Creative Commons licence and your intended use is not permitted by statutory regulation or exceeds the permitted use, you will need to obtain permission directly from the copyright holder. To view a copy of this licence, visit http://creativecommons.org/licenses/by/4.0/. The Creative Commons Public Domain Dedication waiver (http://creativecommons.org/publicdomain/zero/1.0/) applies to the data made available in this article, unless otherwise stated in a credit line to the data. 
to ageing, it can also be accelerated with increased CVD risk factors and inflammation (early vascular ageing). Arterial stiffness eventually results in higher driving pressures and increased energy demands for the heart, while leading to higher diastolic-systolic pressure differences (i.e. widening of pulse pressure). Increased arterial pressures and pulsatility impose higher mechanical stress on the vessels and organs, leading to strong associations between arterial stiffness and organ damage in the heart, kidney or brain [13].

With the aorta being the major elastic vessel in the body, aortic stiffness likely represents the most informative measurement of arterial stiffness [13]. Amongst the several principles, techniques and devices that have been proposed to measure arterial stiffness in humans, Doppler echocardiography is one of the cheapest, fast, widely available and reliable methods to assess aortic stiffness. Moreover, it can be easily integrated into a routine echocardiography assessment.

Aortic stiffness was significantly increased in RA patients [14-16], and it was associated with worse CVD outcomes [17]. Interestingly, treatment with conventional synthetic disease-modifying anti-rheumatic drugs (csDMARDs) or tumour necrosis factor inhibitors (TNFi) appeared to be the effective strategy to improve aortic stiffness in early RA patients [14, 18, 19].

Most clinical trials have been successful at demonstrating a beneficial effect of csDMARDs and TNFi on CV outcomes in RA of short duration [20-22], when CVD risk profile is still favourable and inflammation is at its highest. However, patients with RA are subject to great accumulation of CVD risk factors in a disproportionate manner than the general population and this can happen even when RA patients receive long-term therapy with good outcomes in terms of disease activity control [23-26]. In such patients with long-standing and established disease, whether csDMARDs and TNFi can still have an effect on aortic stiffness is largely unknown. This knowledge could encourage retention of csDMARDs or TNFi for their CV benefit beyond the control of inflammation. The aim of this study was to comparatively describe aortic stiffness progression in such RA patients treated with csDMARDs and TNFi.

\section{Methods}

\section{Study protocol}

This was a post hoc analysis of a wider cross-sectional study of cardiovascular assessment of non-institutionalized individuals $>18$ years of age affected with rheumatic and musculoskeletal diseases, which was started in 2014 at the Division of Rheumatology, Department of Medicine, University and Azienda Ospedaliera Universitaria Integrata of Verona (Italy). The study was approved by the institutional review board of the University of Verona (1707CESC) and conformed to the ethical guidelines of the Declaration of Helsinki as revised in 2000. All patients gave written informed consent signing a specific institutional consent form. Inclusion criteria comprised a diagnosis of RA according to the 2010 ACR/EULAR definition. Furthermore, we consulted medical notes to assess whether significant changes in medications had been recorded, so that all patients who did not change DMARD treatment during follow-up were selected for the study. The following exclusion criteria were applied: previous CVD diagnoses, events, and procedures (any known CVD including myocardial infarction, stroke, coronary revascularization, transient ischaemic attack, hospitalization for unstable angina, peripheral artery disease, symptomatic carotid artery disease, and uncontrolled systemic arterial hypertension). Patients who had started CV or RA medications within 6 weeks from the first assessment were also excluded from this analysis. All participants underwent an evaluation of cardiovascular risk factors and were offered echocardiography examination, carotid ultrasound and aortic stiffness assessment. Follow-up and instrumental assessments were performed yearly.

\section{Patient disposition}

Participants were consecutively screened and recruited from March 2014 to March 2016. All recruited patients underwent a clinical evaluation by senior rheumatologists (OV, DG, LI) including assessments of disease activity, disease duration, body weight and height, medical history and $\mathrm{CV}$ and RA medications. Recruited patients were then referred for aortic stiffness assessment that was performed within 2 weeks. Laboratory tests including inflammatory markers, serology, lipids and glucose levels were performed within 2 weeks before or after aortic stiffness assessment. Follow-up assessments at 12 months were performed between March 2015 and March 2017. All patients in the TNFi group received a combination of csDMARDs and TNFi.

\section{Cardiovascular disease risk factors}

The following CVD risk factors were collected: age; gender; systolic blood pressure (SBP), diastolic blood pressure (DBP) and heart rate were measured at the end of echocardiographic evaluation in supine position; weight and height with the calculation of body mass index (BMI); lipids including total cholesterol, low-density cholesterol and high-density cholesterol, and triglycerides; waist circumference; renal function; and smoking status. We defined obesity when body mass index (BMI) $\geq 30 \mathrm{~kg} / \mathrm{m}^{2}$. Dyslipidaemia was defined as levels of total serum cholesterol $>190 \mathrm{mg} / \mathrm{dL}$ and or triglycerides $>150$ $\mathrm{mg} / \mathrm{dL}$ or pharmacologically treated high lipid serum levels. To assess renal function, we considered the glomerular filtration rate (GFR) estimated with the CKD-EPI 
equation and defined renal dysfunction as estimated GFR $<60 \mathrm{ml} / \mathrm{min} 1.73 \mathrm{~m}^{2}$.

\section{Rheumatoid arthritis-associated factors}

Data on disease duration, anti-citrullinated peptides antibodies (ACPA) and rheumatoid factor (RF) were collected. Serum biomarkers of RA-related inflammation (C-reactive protein CRP, and ESR) were measured. RA disease activity was evaluated by the clinical disease activity index (CDAI) score and disease-activity score in 28-joints (DAS28). Patients were defined as having remission, low, moderate or high disease activity according to CDAI values. Current immunomodulating agents including conventional synthetic DMARDs and biologic DMARDs, glucocorticoid use and dose (in prednisoneequivalent milligrams daily), and NSAID use were recorded.

\section{Aortic stiffness assessment}

Aortic stiffness was evaluated by Doppler echocardiography. All Doppler echocardiographic studies were performed by an expert sonographer (FO) using an Alpha Esaote Biomedica machine (Florence, Italy) equipped with a $2.5-3.5 \mathrm{MHz}$ annular-array transducer and following a standardized protocol. Images were stored on compact disks or magneto-optical disks and forwarded for final interpretation to a senior cardiologist (GC) blinded to the identity of the subject. Aortic stiffness was assessed at the level of the aortic root, using a twodimensional guided M-mode evaluation of systolic (AoS) and diastolic (AoD) aortic diameters, $3 \mathrm{~cm}$ above the aortic valve together with blood pressure measured by cuff sphygmomanometer. AoD was obtained at the peak of the $\mathrm{R}$ wave at the simultaneously recorded electrocardiogram, while AoS was measured at the maximal anterior motion of the aortic wall $[27,28]$; for each diameter, five measurements were averaged. Values of SBP, DBP, AoS and AoD were used to calculate the aortic stiffness index (AoSI) using the following validated formula: AoSI $=\ln (\mathrm{SBP} / \mathrm{DBP}) /(\mathrm{AoS}-\mathrm{AoD}) / \mathrm{AoD}$. Intraclass correlation coefficient (ICC) with a two-way random model was used to assess the absolute reliability of aortic diameters and BP measurement in 50 patients. ICC values $(95 \%$ CI) were $0.91(0.86-0.94)$ for $\mathrm{AoS}, 0.93$ for $\mathrm{AoD}, 0.92$ for SBP and 0.94 for DBP respectively. ICC for calculated AoSI was 0.92 .

\section{Statistical analysis}

Continuous data are reported as mean values \pm standard deviation (SD) or absolute numbers (percentage) for categorical variables. Treatment group comparisons of categorical variables were performed by chi-squared or Fisher test as appropriate; for continuous variables, independent samples T-test was used. Paired samples T-test was used to determine significant changes from baseline of continuous variables including AoSI, arterial blood pressure, lipids, glucose, inflammatory markers and RA disease activity scores. Treatment group comparisons of follow-up AoSI were performed in the whole study population using two-way analysis of covariance (ANCOVA) with Sidak's correction for multiple comparisons, with treatment group and the number of CVD risk factors categorized into three groups $(0-1,2-3$, or $>3)$ as factors, and baseline AoSI, age and SBP as covariates. The choice of covariates was made upon prior data from our study [17]. All analyses were performed using the statistical package SPSS 22.0 (SPSS Inc. Chicago. Illinois), and statistical significance was identified by two-tailed $p<0.05$. Figures were obtained using the GraphPad Prism software version 7.00.

\section{Results}

Baseline characteristics of csDMARDs and TNFi patients The study population consisted of 107 white RA individuals, 43 patients in the csDMARDs group and 67 in the TNFi group. All patients had established RA and disease duration longer than 2 years. Most patients (74\%) were in remission or low-disease activity, while disease activity was moderate only in $26 \%$ and high in none. High values of ESR $(>40 \mathrm{~mm} / \mathrm{h})$ or CRP $(>10 \mathrm{mg} / \mathrm{L})$ were found in $11.8 \%$ and $8 \%$ only, respectively. Excluding age and sex, 92\% of RA patients had at least one CVD risk factor, $58 \%$ two or more and $26 \%$ three or more. There were more than two CV risk factors in $28.6 \%$ of csDMARDs and $29.0 \%$ of TNFi groups, respectively $(p=0.469)$. Patients in the csDMARDs and TNFi groups were equally balanced for the proportion of CVD risk factors and medications, and there were no significant differences in baseline SBP, DBP or serum lipids. The proportions of patients taking angiotensin-converting enzyme and angiotensin II receptor blockers, calcium channel antagonists, diuretics or beta-blockers were not significantly different between the two groups. With regard to RA characteristics, the two groups differed only for greater use of hydroxychloroquine in the csDMARD group (Table 1).

\section{Reduced aortic stiffness progression with TNFi compared to csDMARDs}

The two groups did not differ significantly for baseline AoSI $(5.95 \pm 3.73 \%$ vs $6.08 \pm 4.20 \%, p=0.867)$. However, follow-up AoSI was significantly increased in the csDMARDs group (mean difference $1.00 \%, 95 \%$ CI 0.59 , $1.42 ; p<0.0001$ ) but not in the TNFi group (mean difference $0.15 \%, 95 \% \mathrm{CI}-0.28,0.60, p=0.477)$. Patients on TNFi had significantly lower follow-up AoSI than the csDMARD group $(6.11 \pm 0.18 \%$ vs $7.13 \pm 0.22 \%$; adjusted 
Table 1 Baseline characteristics of the study population

\begin{tabular}{|c|c|c|c|}
\hline Variables & csDMARDs $(n=43)$ & TNFi $(n=64)$ & $P$-value \\
\hline \multicolumn{4}{|l|}{ Cardiovascular disease risk factors } \\
\hline Age, median years (IQR) & $58.6(53.0,66.0)$ & $58.1(49.3,67.0)$ & 0.839 \\
\hline Female sex & $33(76.7)$ & $54(84.4)$ & 0.321 \\
\hline Obesity & $5(11.6)$ & $7(10.9)$ & 0.999 \\
\hline Hypertension & $19(44.2)$ & $30(46.9)$ & 0.784 \\
\hline Anti-hypertensive drug & $17(39.5)$ & $28(43.8)$ & 0.784 \\
\hline Smoking status, ever & $18(42.9)$ & $30(46.9)$ & 0.684 \\
\hline Dyslipidaemia & $30(40.2)$ & $34(59.8)$ & 0.085 \\
\hline Current statin use & $13(34.2)$ & $10(15.9)$ & 0.033 \\
\hline Diabetes mellitus & $3(7.0)$ & $3(4.7)$ & 0.676 \\
\hline Anti-diabetic medication & $1(2.3)$ & $1(1.5)$ & 0.999 \\
\hline CVD risk factors, median (IQR) & $2(1,3)$ & $2(1,3)$ & 0.199 \\
\hline \multicolumn{4}{|c|}{ Rheumatoid arthritis characteristics and treatment } \\
\hline RF and/or ACPA positive & $28(65.1)$ & $33(51.6)$ & 0.165 \\
\hline Disease duration, median years (IQR) & $14.1(11.5)$ & $15.4(10.5)$ & 0.538 \\
\hline Methotrexate & $38(88.4)$ & $52(81.3)$ & 0.192 \\
\hline Leflunomide & $5(17.9)$ & $12(19.0)$ & 0.999 \\
\hline Hydroxychloroquine & $9(31.0)$ & $5(7.8)$ & 0.009 \\
\hline Prednisone $>5$ mg daily & $7(7.7)$ & $5(5.5)$ & 0.823 \\
\hline NSAIDs & $6(20.7)$ & $22(34.4)$ & 0.227 \\
\hline
\end{tabular}

$A C P A$, anti-citrullinated peptides antibodies; CSDMARDs, conventional synthetic disease-modifying anti-rheumatic drugs; IQR, interquartile range; $N S A I D s$, nonsteroidal anti-inflammatory drugs; $R F$, rheumatoid factor; $T N F$, tumour necrosis factor inhibitors. All data reported as absolute numbers (percentage) otherwise specified. P-value refers to the chi-squared or Fisher test for categorical variables or independent samples T-test for continuous variables

mean difference, aMD $-1.02,95 \% \mathrm{CI}-1.581,-0.457, p<$

0.001; ANCOVA).

\section{Interaction of treatment and CVD risk factors on aortic} stiffness

There was a statistically significant two-way interaction between the treatment group and the number of CVD risk factors on AoSI at follow-up, while controlling for baseline AoSI, age and SBP $\left(p<0.0001, \eta^{2}=0.038\right)$. Follow-up AoSI was lower in the TNFi compared to csDMARDs group (Fig. 1) both when CVD risk factors were 1-2 (aMD $-1.143,95 \%$ CI $-2.102,-0.185, p=0.019)$ and when CVD risk factors were more than two (aMD -4.806 , 95\% CI $-6.128,-3.484, p<0.001)$. We also compared the effect on aortic stiffness of TNFi and csDMARDs therapy across RA patients according to the presence of the most prevalent CVD risk factors in our study population: hypertension, dyslipidaemia and smoking. Adjusted AoSI means at follow-up were significantly higher than baseline in the csDMARDs group but not in the TNFI group (Fig. 2).

Changes in lipids, glucose and blood pressure induced by DMARD therapy.

Overall, favourable changes in lipids and glucose after DMARD therapy were found (Table 2). There was a

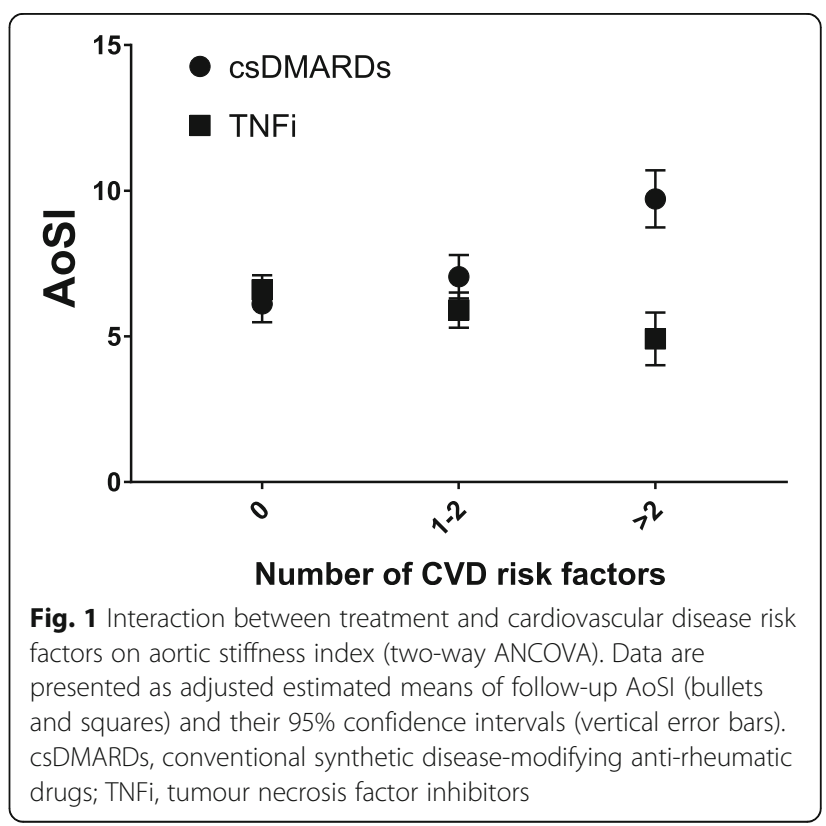




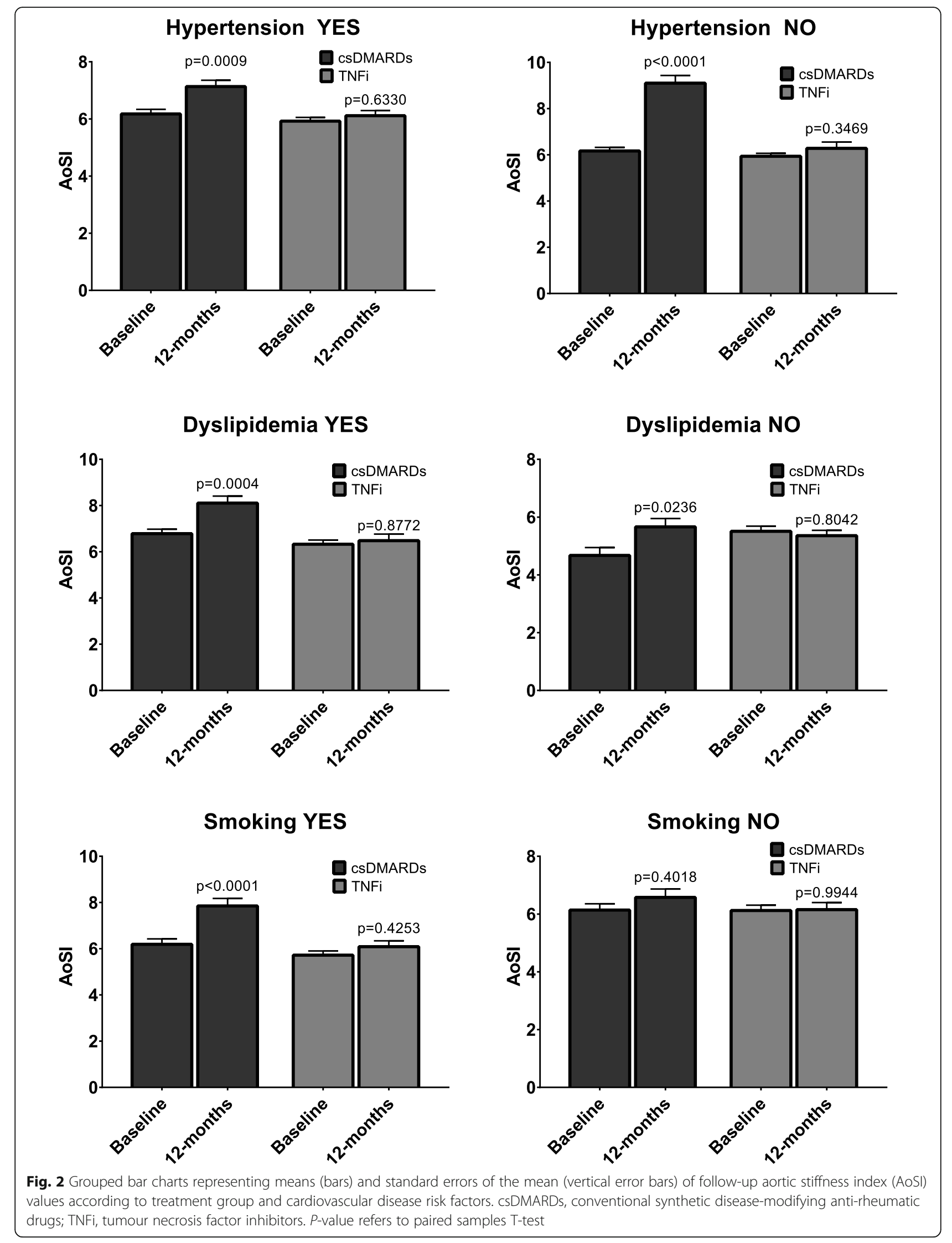


Table 2 Longitudinal changes in CVD risk factors and RA disease activity according to treatment group

\begin{tabular}{|c|c|c|c|c|c|c|}
\hline & \multicolumn{3}{|c|}{ csDMARDs } & \multicolumn{3}{|l|}{ TNFi } \\
\hline & Baseline & 12 months & $P$-value & Baseline & 12 months & $P$-value \\
\hline \multicolumn{7}{|c|}{ Cardiovascular disease risk factors } \\
\hline TGL & $123(68)$ & $114(50)$ & $<0.001$ & $113(48)$ & $106(46)$ & 0.023 \\
\hline LDL & $122(32)$ & $112(19)$ & $<0.001$ & $125(26)$ & $126(30)$ & 0.535 \\
\hline $\mathrm{HDL}$ & $69(12)$ & $66(10)$ & $<0.001$ & $74(22)$ & $74(19)$ & 0.609 \\
\hline TC & $212(3)$ & $200(19)$ & $<0.001$ & $221(30)$ & $218(38)$ & 0.161 \\
\hline SFG & $88(8)$ & $85(15)$ & $<0.001$ & $94(13)$ & $91(11)$ & 0.001 \\
\hline SBP & $130(19)$ & $135(19)$ & $<0.001$ & $136(19)$ & $135(21)$ & 0.152 \\
\hline DBP & $80(10)$ & $83(11)$ & $<0.001$ & $86(10)$ & $82(10)$ & $<0.001$ \\
\hline BMI & $25.5(4.5)$ & $25.5(4.5)$ & 0.442 & $25.6(4.1)$ & $25.6(4.1)$ & 0.226 \\
\hline \multicolumn{7}{|c|}{ Rheumatoid arthritis disease activity } \\
\hline ESR & $20(20)$ & $16(17)$ & $<0.001$ & $20(17)$ & $19(14)$ & 0.001 \\
\hline CRP & $5.7(8.2)$ & $4.6(8.7)$ & $<0.001$ & $2.40(2.51)$ & $2.49(2.15)$ & 0.410 \\
\hline CDAl & $10(10)$ & $10(10)$ & 0.173 & $9(7)$ & $11(10)$ & $<0.001$ \\
\hline DAS28 & $2.05(1.35)$ & $2.54(1.36)$ & 0.002 & $2.64(0.77)$ & $2.81(1.23)$ & 0.108 \\
\hline
\end{tabular}

$A O S I$, aortic stiffness index; $B M I$, body mass index, $C D A l$, clinical disease activity score index; $C R P, C$-reactive protein; $c S D M A R D s$, conventional synthetic diseasemodifying anti-rheumatic drugs; $D A S 28$, disease activity score-28; $D B P$, diastolic blood pressure; $E S R$, erythrocyte sedimentation rate; $H D L$; high-density lipoprotein; $L D L$, low-density lipoprotein; SBP, systolic blood pressure; SFG, serum fasting glucose; $T C$, total cholesterol; TGL, triglycerides; $T N F i$, tumour necrosis factor inhibitors. All data reported as mean (standard deviation). P-value refers to paired samples t-test comparisons between values at baseline and 12 months

significant reduction in TC, VLDL, LDL and HDL in the csDMARDs group. SFG was reduced both in the csDMARDs and TNFi group. However, blood pressure (both SBP and DBP) was significantly increased in the csDMARDs group, whereas DBP was significantly decreased in the TNFi group. We found no significant correlations between changes in AoSI and serum lipids, glucose or arterial blood pressure.

\section{Discussion}

The original finding of this study is showing that arterial stiffness progression can be hampered by TNFi not only in early but even in long-standing RA. Those individuals show a greater number of CVD risk factors than early RA patients [29] and higher CVD mortality than the general population [1]. Hence, control of CVD risk in such patients is the most important outcome to achieve along with control of disease activity.

Prior studies on the effect of TNFi on arterial stiffness focused on early RA patients with short disease duration and relatively low CVD risk. We noticed favourable effects in terms of reduction of aortic stiffness with TNFi compared to csDMARDs in a cohort of patients with several CVD risk factors. TNFi can reduce endothelial dysfunction and reduce carotid intima-media thickness [30]. Skin microvascular responses assessed by laser Doppler imaging improved in patients with active RA and no previous history of CVD who responded to TNFi or MTX [31]. Short-term treatment with TNFi also increased circulating endothelial progenitor cells concurrently with a proportional decrease of disease activity [32]. Our results, along with the previous evidence, are consistent with the hypothesis that the vascular-protective effect could be effectively achieved by inhibition of TNF [33].

The effect of TNFi on arterial stiffness in RA was deemed to be independent of the reduction of systemic inflammation in patients with very high disease activity [19]. Herein, the proportion of patients with high disease activity was very low; hence, we provided further evidence that the beneficial effect of TNF-alpha inhibition on arterial stiffness goes beyond the DMARD-associated reduction of systemic inflammation. Indeed, we also found no association between inflammatory markers or disease activity scores and aortic stiffness. However, the relationship between disease activity and AoSI was difficult to ascertain as all changes in disease activity scores were subtle and non-clinically meaningful, as they did not lead to treatment changes.

The third result of our study is that TNFi may be more beneficial than csDMARDs in presence of some CVD risk factors such as hypertension, dyslipidaemia and smoking. Although traditional CV risk factors alone do not explain the heightened risk of CVD in RA [34], a meta-analysis confirmed hypertension, type $2 \mathrm{DM}$, smoking and hypercholesterolaemia as key traditional factors increasing the risk of CVD in RA [35]. Hence, we analysed changes in aortic stiffness according to the presence of each of these CVD risk factors, except for DM due to the scarcity of patients with DM in our study population. 
There was a sharp cardiovascular benefit of TNFi over csDMARDs in hypertensive RA patients. Moreover, TNFi therapy significantly decreased DBP values at follow-up, while SBP and DBP were both increased in the csDMARDs group. Essential hypertension was reported in up to $57 \%$ of patients with RA and can predict CV events (HR 3.67, 95\% CI 2.0, 6.4, $p=0.001$ ) [36]. Several small studies support the potential BP-lowering effect of TNFi in RA patients [37]. Nonetheless, in a US epidemiological study of RA patients, treatment with TNFi did not reduce the risk of incident hypertension compared with nonbDMARDs [38]. Interestingly, we showed that TNFi decreased AoSI and DBP also in normotensive RA patients, suggesting that the main driver of decreased $\mathrm{BP}$ is the TNFi-mediated favourable effect on arterial stiffness.

Patients with RA and dyslipidaemia on TNFi also showed reduced arterial stiffness. Moreover, 1 year of therapy with TNFi did not increase blood lipids, a finding that is in line with a meta-analysis of $25 \mathrm{RCTs}$ of patients with chronic inflammatory arthritis that failed to demonstrate an effect of TNFi on TC, HDL-C and LDLC [39]. Similar results were obtained by a recent RCT investigating the cardiovascular safety of tocilizumab against etanercept [40]. Conversely, there was a significant reduction of lipids with csDMARDs despite worse results on the progression of aortic stiffness, suggesting that arterial stiffness in RA may be scarcely associated with serum lipid levels. This finding can be partially explained by the higher number of patients taking HCQ in the csDMARD group. Although HCQ confers limited efficacy on disease activity and progression of RA, HCQ increases HDL and reduces levels of TC, LDL-C and triglycerides [41]. Additionally, we noticed decreased glucose across treatment groups, consistent with the lower incidence of diabetes with the use of HCQ [41, 42] or TNFi [42] amongst RA patients.

Finally, we showed an effect on arterial stiffness of TNFi therapy in smokers. Cigarette smoking is the strongest known lifestyle or environmental risk factor for RA [25, 43-45] and RA treatment failure [46]. Moreover, smoking can damage the vascular wall, possibly leading to impaired prostacyclin production and enhanced platelet-vessel wall interactions [47]. This can reduce the elastic properties of the aorta, resulting in stiffening and trauma to the wall [48]. Smoking, as well as passive exposure to smoke, impairs endotheliumdependent vasodilation of normal coronary arteries and reduces coronary flow reserve [49-53]. Smoking can also potentiate the endothelial dysfunction induced by hypercholesterolaemia [54].

\section{Study limitations and strengths}

The main strength of this study consists of including a real-life cohort of RA patients with long-standing disease, several CVD risk factors and stable treatment. This kind of patient represents most patients we manage daily in our outpatient clinics. We used a prospective design, stringent entry criteria and a reliable method for the assessment of aortic stiffness which could be easily implemented in clinical practice. With regard to study limitations, we have to underline the relatively small sample size and the cross-sectional design of the study (patients were not randomized for treatment arms). Disease activity and lifestyle modifications are difficult to evaluate outside a clinical trial, but the vast majority of patients had stable disease activity and behavioural changes were very rare and of minimal clinical impact. Furthermore, we certainly cannot draw conclusions on RA patients on non-TNFi biologics as they were not included. Moreover, we could not substantiate a reduction of CVD events in RA patients with decreased arterial stiffness as the study was not powered for this outcome. Finally, smoking status was recorded as a binomial variable (ever vs never) and the number of pack-years was not calculated.

\section{Clinical implications and conclusions}

Long-standing RA is commonly managed in rheumatology outpatient clinics. Our results seem to indicate that TNFi treatment could be associated with reduced arterial stiffness in patients with established, long-standing RA with several CVD risk factors. Although long-term TNFi therapy can be challenging due to the high CVD burden, our data encourage the assessment of AoSI in RA patients and maintain TNFi therapy whereas AoSI is abnormally high. This can be particularly relevant in such RA patients at high CVD risk.

\section{Acknowledgements}

None.

\section{Patient and public involvement statement}

This research was done without direct patient involvement. Patients were not invited to comment on the study design and were not consulted to develop patient-relevant outcomes or interpret the results. Patients were not invited to contribute to the writing or editing of this document for readability or accuracy.

\section{Transparency declaration}

The lead author (the manuscript's guarantor) affirms that the manuscript is an honest, accurate and transparent account of the study being reported; that no important aspects of the study have been omitted; and that any discrepancies from the study as planned (and, if relevant, registered) have been explained.

\section{Authors' contributions}

AG, OV and MR provided the conception of the study. AG provided literature search, contributed to the data collection and interpretation and drafting of the article and revised it critically for important intellectual content. GO, AF and RB provided data collection. FO and GC performed the blinded assessment of ultrasound scans. GC, RB, AD and GA provided data search, contributed to the interpretation of the data and drafting of the article and revised it critically for important intellectual content. OV, DG and $\mathrm{LI}$

performed the clinical assessments. All authors revised the article critically for 
important intellectual content and gave final approval of the version to be submitted.

\section{Funding}

No author received any financial support or other benefits from commercial sources for this work. This research did not receive any specific grant from funding agencies in the public, commercial or not-for-profit sectors.

\section{Availability of data and materials}

Data sharing is not applicable to this article; please contact the corresponding author for data requests.

\section{Declarations}

\section{Ethics approval and consent to participate}

All patients gave written informed consent signing a specific institutional consent form; the study was approved by the institutional review board of the University of Verona (1707CESC) and conformed to the ethical guidelines of the Declaration of Helsinki as revised in 2000.

\section{Consent for publication}

Not applicable (the manuscript does not contain any individual person data).

\section{Competing interests}

The authors declare that they have no competing interests. All authors have completed the ICMJE uniform disclosure form at www.icmje.org/coi_ disclosure.pdf (available on request from the corresponding author) and declare no conflicts of interest.

\section{Author details}

${ }^{1}$ Rheumatology Section, Department of Medicine, University of Verona Hospital Trust, Policlinico G.B. Rossi 10, 37134 Verona, Italy. ${ }^{2}$ Division of Rheumatology, University of Padova, Padua, Italy. ${ }^{3}$ Division of Cardiac Rehabilitation, S. Pancrazio Hospital, Arco di Trento, Trento, Italy. ${ }^{4}$ Internal Medicine and Hypertension Section, Department of Medicine, University of Verona Hospital Trust, Verona, Italy.

\section{Received: 8 December 2020 Accepted: 24 May 2021}

\section{Published online: 03 June 2021}

\section{References}

1. Aviña-Zubieta JA, Thomas J, Sadatsafavi M, Lehman AJ, Lacaille D. Risk of incident cardiovascular events in patients with rheumatoid arthritis: a metaanalysis of observational studies. Ann Rheum Dis. 2012 Sep;71(9):1524-9. https://doi.org/10.1136/annrheumdis-2011-200726.

2. Aviña-Zubieta JA, Choi HK, Sadatsafavi M, Etminan M, Esdaile JM, Lacaille D. Risk of cardiovascular mortality in patients with rheumatoid arthritis: a metaanalysis of observational studies. Arthritis Rheum. 2008 Dec 15;59(12):16907. https://doi.org/10.1002/art.24092.

3. Klocke R, Cockcroft JR, Taylor GJ, Hall IR, Blake DR. Arterial stiffness and central blood pressure, as determined by pulse wave analysis, in rheumatoid arthritis. Ann Rheum Dis. 2003 May;62(5):414-8. https://doi. org/10.1136/ard.62.5.414.

4. Prati C, Demougeot C, Guillot X, Godfrin-Valnet M, Wendling D. Endothelial dysfunction in joint disease. Joint Bone Spine. 2014 Feb 22:81(5):386-91. https://doi.org/10.1016/j.jbspin.2014.01.014.

5. Moroni L, Selmi C, Angelini C, Meroni PL. Evaluation of endothelial function by flow-mediated dilation: a comprehensive review in rheumatic disease. Arch Immunol Ther Exp. 2017 Dec;65(6):463-75. https://doi.org/10.1007/ s00005-017-0465-7.

6. Kotani $\mathrm{K}$, Miyamoto $\mathrm{M}$, Ando $\mathrm{H}$. The effect of treatments for rheumatoid arthritis on endothelial dysfunction evaluated by flow-mediated vasodilation in patients with rheumatoid arthritis. Curr Vasc Pharmacol. 2017;15(1):10-8. https://doi.org/10.2174/1570161114666161013113457.

7. Gonzalez-Gay MA, Gonzalez-Juanatey C, Vazquez-Rodriguez TR, Martin J, Llorca J. Endothelial dysfunction, carotid intima-media thickness, and accelerated atherosclerosis in rheumatoid arthritis. Semin Arthritis Rheum. 2008 Oct;38(2):67-70. https://doi.org/10.1016/j.semarthrit.2008.02.001.

8. Bordy R, Totoson P, Prati C, Marie C, Wendling D, Demougeot C. Microvascular endothelial dysfunction in rheumatoid arthritis. Nat Rev Rheumatol. 2018;14(7):404-20. https://doi.org/10.1038/s41584-018-0022-8.
9. Cavalcante JL, Lima JAC, Redheuil A, Al-Mallah MH. Aortic stiffness: current understanding and future directions. J Am Coll Cardiol. 2011 Apr 5;57(14): 1511-22. https://doi.org/10.1016/j.jacc.2010.12.017.

10. Cohn JN, Quyyumi AA, Hollenberg NK, Jamerson KA. Surrogate markers for cardiovascular disease: functional markers. Circulation. 2004 Jun 29; 109(25 Suppl 1):IV31-46. https://doi.org/10.1161/01.CIR.0000133442.991 86.39

11. Vlachopoulos C, Aznaouridis K, Stefanadis C. Prediction of cardiovascular events and all-cause mortality with arterial stiffness: a systematic review and meta-analysis. J Am Coll Cardiol. 2010 Mar 30;55(13):1318-27. https://doi. org/10.1016/j.jacc.2009.10.061.

12. Segers $P$, Rietzschel $E R$, Chirinos JA. How to measure arterial stiffness in humans. Arterioscler Thromb Vasc Biol. 2020 May;40(5):1034-43. https://doi. org/10.1161/ATVBAHA.119.313132.

13. Chirinos JA, Segers $P$, Hughes $T$, Townsend R. Large-artery stiffness in health and disease: JACC state-of-the-art review. J Am Coll Cardiol. 2019;74(9): 1237-63. https://doi.org/10.1016/j.jacc.2019.07.012.

14. Tam LH-P, Shang Q, Li EK-M, Wong PC-H, Kwok KY, Kun EW-L, et al. Effect of treat-to-target strategies aiming at remission of arterial stiffness in early rheumatoid arthritis: a randomized controlled study. J Rheumatol. 2018; 45(9):1229-39. https://doi.org/10.3899/jrheum.171128.

15. Kocabay G, Hasdemir H, Yildiz M. Evaluation of pulse wave velocity in systemic lupus erythematosus, rheumatoid arthritis and Behçet's disease. Journal of Cardiology. 2012 Jan 1;59(1):72-7. https://doi.org/10.1016/j.jjcc.2011.09.004.

16. Provan SA, Semb AG, Hisdal J, Stranden E, Agewall S, Dagfinrud H, et al. Remission is the goal for cardiovascular risk management in patients with rheumatoid arthritis: a cross-sectional comparative study. Ann Rheum Dis. 2011 May 1;70(5):812-7. https://doi.org/10.1136/ard.2010.141523.

17. Cioffi G, Viapiana O, Ognibeni F, Dalbeni A, Orsolini G, Adami S, et al. Clinical profile and outcome of patients with rheumatoid arthritis and abnormally high aortic stiffness. Eur J Prev Cardiolog. 2016 Nov 1;23(17): 1848-59. https://doi.org/10.1177/2047487316649762.

18. Tam L-S, Shang Q, Li EK, Wang S, Li R-J, Lee K-L, et al. Infliximab is associated with improvement in arterial stiffness in patients with early rheumatoid arthritis - a randomized trial. J Rheumatol. 2012 Dec 1;39(12): 2267-75. https://doi.org/10.3899/jrheum.120541.

19. Plein S, Erhayiem B, Fent G, Horton S, Dumitru RB, Andrews J, et al. Cardiovascular effects of biological versus conventional synthetic diseasemodifying antirheumatic drug therapy in treatment-naive, early rheumatoid arthritis. Ann Rheum Dis. 2020 Nov;79(11):1414-22. https://doi.org/10.1136/a nnrheumdis-2020-217653.

20. Burggraaf B, van Breukelen-van der Stoep DF, de Vries MA, Klop B, Liem AH, van de Geijn G-JM, et al. Effect of a treat-to-target intervention of cardiovascular risk factors on subclinical and clinical atherosclerosis in rheumatoid arthritis: a randomised clinical trial. Ann Rheum Dis. 2019;78(3): 335-41. https://doi.org/10.1136/annrheumdis-2018-214075.

21. Bissell L-A, Hensor EMA, Kozera L, Mackie SL, Burska AN, Nam JL, et al. Improvement in insulin resistance is greater when infliximab is added to methotrexate during intensive treatment of early rheumatoid arthritis-results from the IDEA study. Rheumatology. 2016 Dec;55(12):2181-90. https://doi. org/10.1093/rheumatology/kew306.

22. Charles-Schoeman C, Yin Lee Y, Shahbazian A, Wang X, Elashoff D, Curtis JR, et al. Improvement of high-density lipoprotein function in patients with early rheumatoid arthritis treated with methotrexate monotherapy or combination therapies in a randomized controlled trial. Arthritis Rheumatol. 2017:69(1):46-57. https://doi.org/10.1002/art.39833.

23. Mortimer I, Bissell L-A, Hensor EMA, Kozera L, Mackie SL, Burska AN, et al. Improvement in cardiovascular biomarkers sustained at 4 years following an initial treat-to-target strategy in early rheumatoid arthritis. Rheumatology. 2019:58(9):1684-6.

24. Jafri K, Bartels CM, Shin D, Gelfand JM, Ogdie A. Incidence and management of cardiovascular risk factors in psoriatic arthritis and rheumatoid arthritis: a population-based study. Arthritis Care Res. 2017;69(1): 51-7. https://doi.org/10.1002/acr.23094.

25. Sugiyama D, Nishimura K, Tamaki K, Tsuji G, Nakazawa T, Morinobu A, et al. Impact of smoking as a risk factor for developing rheumatoid arthritis: a meta-analysis of observational studies. Ann Rheum Dis. 2010 Jan;69(1):7081. https://doi.org/10.1136/ard.2008.096487.

26. England BR, Roul P, Yang Y, Sayles H, Yu F, Michaud K, et al. Burden and trajectory of multimorbidity in rheumatoid arthritis: a matched cohort study from 2006 to 2015. Ann Rheum Dis. 2021;80:286-92. 
27. Nistri S, Grande-Allen J, Noale M, Basso C, Siviero P, Maggi S, et al. Aortic elasticity and size in bicuspid aortic valve syndrome. Eur Heart J. 2008 Feb, 29(4):472-9. https://doi.org/10.1093/eurheartj/ehm528.

28. Stefanadis C, Stratos C, Boudoulas H, Kourouklis C, Toutouzas P. Distensibility of the ascending aorta: comparison of invasive and non-invasive techniques in healthy men and in men with coronary artery disease. Eur Heart J. 1990 Nov;11(11):990-6. https://doi.org/10.1093/oxfordjournals.eurheartj.a059639.

29. England BR, Thiele GM, Anderson DR, Mikuls TR. Increased cardiovascular risk in rheumatoid arthritis: mechanisms and implications. BMJ. 2018;361: k1036. https://doi.org/10.1136/bmj.k1036.

30. Del Porto F, Laganà B, Lai S, Nofroni I, Tinti F, Vitale M, et al. Response to anti-tumour necrosis factor alpha blockade is associated with reduction of carotid intima-media thickness in patients with active rheumatoid arthritis. Rheumatology. 2007 Jul 1;46(7):1111-5. https://doi.org/10.1093/rheuma tology/kem089.

31. Galarraga B, Belch JJF, Pullar T, Ogston S, Khan F. Clinical improvement in rheumatoid arthritis is associated with healthier microvascular function in patients who respond to antirheumatic therapy. J Rheumatol. 2010 Mar; 37(3):521-8. https://doi.org/10.3899/jrheum.090417.

32. Spinelli FR, Metere A, Barbati C, Pierdominici M, lannuccelli C, Lucchino B, et al. Effect of therapeutic inhibition of TNF on circulating endothelial progenitor cells in patients with rheumatoid arthritis. Mediators Inflamm. 2013;2013(537539). https://doi.org/10.1155/2013/537539.

33. Giollo A, Bissell L-A, Buch MH. Cardiovascular outcomes of patients with rheumatoid arthritis prescribed disease modifying anti-rheumatic drugs: a review. Expert Opin Drug Saf. 2018;17(7):697-708. https://doi.org/10.1080/14 740338.2018.1483331.

34. Del Rincón ID, Williams K, Stern MP, Freeman GL, Escalante A. High incidence of cardiovascular events in a rheumatoid arthritis cohort not explained by traditional cardiac risk factors. Arthritis Rheum. 2001;44(12): 2737-45. https://doi.org/10.1002/1529-0131(200112)44:12<2737::AID-ART4 60>3.0.CO;2-\#

35. Baghdadi LR, Woodman RJ, Shanahan EM, Mangoni AA. The impact of traditional cardiovascular risk factors on cardiovascular outcomes in patients with rheumatoid arthritis: a systematic review and meta-analysis. PLoS One. 2015;10(2):e0117952. https://doi.org/10.1371/journal.pone.0117952.

36. Innala L, Möller B, Ljung L, Magnusson S, Smedby T, Södergren A, et al. Cardiovascular events in early RA are a result of inflammatory burden and traditional risk factors: a five year prospective study. Arthritis Res Ther. 2011; 13(4):R131. https://doi.org/10.1186/ar3442.

37. Klarenbeek NB, van der Kooij SM, Huizinga TJW, Goekoop-Ruiterman YPM, Hulsmans HMJ, van Krugten MV, et al. Blood pressure changes in patients with recent-onset rheumatoid arthritis treated with four different treatment strategies: a post hoc analysis from the BeSt trial. Ann Rheum Dis. 2010 Jul; 69(7):1342-5. https://doi.org/10.1136/ard.2009.124180.

38. Desai RJ, Solomon DH, Schneeweiss S, Danaei G, Liao KP, Kim SC. Tumor necrosis factor-a inhibitor use and the risk of incident hypertension in patients with rheumatoid arthritis. Epidemiology. 2016 May;27(3):414-22. https://doi.org/10.1097/EDE.0000000000000446.

39. Souto A, Salgado E, Maneiro JR, Mera A, Carmona L, Gómez-Reino JJ. Lipid profile changes in patients with chronic inflammatory arthritis treated with biologic agents and tofacitinib in randomized clinical trials: a systematic review and meta-analysis. Arthritis Rheumatol. 2015 Jan;67(1):117-27. https://doi.org/10.1002/art.38894

40. Giles JT, Sattar N, Gabriel S, Ridker PM, Gay S, Warne C, et al. Cardiovascular safety of tocilizumab versus etanercept in rheumatoid arthritis: a randomized controlled trial. Arthritis Rheumatol. 2020;72(1):31-40. https:// doi.org/10.1002/art.41095.

41. Rempenault C, Combe B, Barnetche T, Gaujoux-Viala C, Lukas C, Morel J, et al. Metabolic and cardiovascular benefits of hydroxychloroquine in patients with rheumatoid arthritis: a systematic review and meta-analysis. Ann Rheum Dis. 2018 Jan;77(1):98-103. https://doi.org/10.1136/a nnrheumdis-2017-211836.

42. Solomon DH, Massarotti E, Garg R, Liu J, Canning C, Schneeweiss S. Association between disease-modifying antirheumatic drugs and diabetes risk in patients with rheumatoid arthritis and psoriasis. JAMA. 2011 Jun 22; 305(24):2525-31. https://doi.org/10.1001/jama.2011.878.

43. Klareskog L, Stolt P, Lundberg K, Källberg H, Bengtsson C, Grunewald J, et al. A new model for an etiology of rheumatoid arthritis: smoking may trigger HLA-DR (shared epitope)-restricted immune reactions to autoantigens modified by citrullination. Arthritis Rheum. 2006 Jan;54(1):38-46. https://doi. org/10.1002/art.21575.

44. Karlson EW, Chang S-C, Cui J, Chibnik LB, Fraser PA, De Vivo I, et al. Geneenvironment interaction between HLA-DRB1 shared epitope and heavy cigarette smoking in predicting incident rheumatoid arthritis. Ann Rheum Dis. 2010 Jan;69(1):54-60. https://doi.org/10.1136/ard.2008.102962.

45. Makrygiannakis D, Hermansson M, Ulfgren A-K, Nicholas AP, Zendman AJW, Eklund $A$, et al. Smoking increases peptidylarginine deiminase 2 enzyme expression in human lungs and increases citrullination in BAL cells. Ann Rheum Dis. 2008 Oct;67(10):1488-92. https://doi.org/10.1136/ard.2007.075192.

46. Saevarsdottir S, Wedrén S, Seddighzadeh M, Bengtsson C, Wesley A, Lindblad S, et al. Patients with early rheumatoid arthritis who smoke are less likely to respond to treatment with methotrexate and tumor necrosis factor inhibitors: observations from the Epidemiological Investigation of Rheumatoid Arthritis and the Swedish Rheumatology Register cohorts. Arthritis Rheum. 2011;63(1):26-36. https://doi.org/10.1002/art.27758.

47. Nowak J, Murray JJ, Oates JA, FitzGerald GA. Biochemical evidence of a chronic abnormality in platelet and vascular function in healthy individuals who smoke cigarettes. Circulation. 1987 Jul 1;76(1):6-14. https://doi.org/1 0.1161/01.CIR.76.1.6.

48. Christodoulos S, Eleftherios T, Charalambos V, Costas S, Konstantinos T, Christos $P$, et al. Unfavorable effect of smoking on the elastic properties of the human aorta. Circulation. 1997 Jan 7;95(1):31-8.

49. Celermajer DS, Adams MR, Clarkson P, Robinson J, McCredie R, Donald A, et al. Passive smoking and impaired endothelium-dependent arterial dilatation in healthy young adults. NEJM. 1996 Jan 18;334(3):150-4. https:// doi.org/10.1056/NEJM199601183340303.

50. Barua RS, Ambrose JA, Eales-Reynolds LJ, DeVoe MC, Zervas JG, Saha DC. Dysfunctional endothelial nitric oxide biosynthesis in healthy smokers with impaired endothelium-dependent vasodilatation. Circulation. 2001 Oct 16; 104(16):1905-10. https://doi.org/10.1161/hc4101.097525.

51. Sumida H, Watanabe H, Kugiyama K, Ohgushi M, Matsumura T, Yasue H. Does passive smoking impair endothelium-dependent coronary artery dilation in women? J Am Coll Cardiol. 1998 Mar 15;31(4):811-5. https://doi. org/10.1016/S0735-1097(98)00010-2.

52. Kaufmann PA. Gnecchi-Ruscone Tomaso, di Terlizzi Marco, Schäfers Klaus P., Lüscher Thomas F., Camici Paolo G. Coronary heart disease in smokers. Circulation. 2000 Sep 12;102(11):1233-8. https://doi.org/10.1161/01.CIR.1 02.11.1233.

53. Celermajer DS, Sorensen KE, Georgakopoulos D, Bull C, Thomas O, Robinson $J$, et al. Cigarette smoking is associated with dose-related and potentially reversible impairment of endothelium-dependent dilation in healthy young adults. Circulation. 1993 Nov;88(5 Pt 1):2149-55. https://doi.org/10.1161/01. CIR.88.5.2149.

54. Johnson HM, Gossett LK, Piper ME, Aeschlimann SE, Korcarz CE, Baker TB, et al. Effects of smoking and smoking cessation on endothelial function: 1year outcomes from a randomized clinical trial. J Am Coll Cardiol. 2010 May 4;55(18):1988-95. https://doi.org/10.1016/j.jacc.2010.03.002.

\section{Publisher's Note}

Springer Nature remains neutral with regard to jurisdictional claims in published maps and institutional affiliations.

Ready to submit your research? Choose BMC and benefit from:

- fast, convenient online submission

- thorough peer review by experienced researchers in your field

- rapid publication on acceptance

- support for research data, including large and complex data types

- gold Open Access which fosters wider collaboration and increased citations

- maximum visibility for your research: over $100 \mathrm{M}$ website views per year

At $\mathrm{BMC}$, research is always in progress.

Learn more biomedcentral.com/submission 